\title{
Parentification and Related Processes: Distinction and Implications for Clinical Practice
}

\section{Stéphanie Haxhe}

To cite this article: Stéphanie Haxhe (2016) Parentification and Related Processes: Distinction and Implications for Clinical Practice, Journal of Family Psychotherapy, 27:3, 185-199, DOI: 10.1080/08975353.2016.1199768

To link to this article: http://dx.doi.org/10.1080/08975353.2016.1199768

曲 Published online: 02 Aug 2016.

Submit your article to this journal \lceil

Q View related articles $₫$

View Crossmark data \lceil 


\title{
Parentification and Related Processes: Distinction and Implications for Clinical Practice
}

\author{
Stéphanie Haxhe \\ Department of Psychology, University of Liège, Liège, Belgium
}

\begin{abstract}
With the emergence of what can be called "new families," the place and the role of the child are increasingly questioned. If a child helps a parent or takes care of them, the terms "parentified child," "parental child," or "adult child" are used equally. However, these concepts hide different processes that have different impacts on the child's development. In the present article, based on the current doctoral research and clinical practice experience, the author will try to make the distinction between these concepts and to illustrate them. By a better identification of each process the author is convinced that therapists and social workers can be helped in their interventions with children and their families.
\end{abstract}

\section{KEYWORDS}

Adultization; delegation; emotional responsibility; family process; parentalization; parentification

Although the parentification concept has existed since the early 1970s, it is often misused and/or confused with other concepts. Most of the time, it is confused with the "parental child" as Minuchin et al. (1967) described it. According to Minuchin, the parental child joins the parental sub-system for defined tasks and periods of time. In this position the child assists with family and parental tasks rather than being a carer for his parents. The two situations are different and have different impacts on a child's development, as will be shown in this article.

The primary concern of this confusion is the diagnosis. Several parentification scales and questionnaires exist (Mika, Bergner, \& Baum, 1987; Hooper, 2011; Sessions \& Jurkovic, 1986). These tools combine emotional and instrumental responsibilities endorsed by the child, as they evaluate two types of parentification: instrumental and emotional. Some items refer to instrumental tasks such as doing the laundry or the dishes, while others refer to emotional tasks like supporting a parent or being a confidant. The problem lies in mixing these items. Chase (2004) reviewed the instruments contributing directly or indirectly to the evaluation of the parentification process, and outlined that none of these measures specifically differentiates instrumental and expressive dimensions of the parentified role. 
If one returns to the texts of Boszormenyi-Nagy and Spark (1973); Boszormenyi-Nagy and Krasner (1986); Bowlby (1977); Minuchin et al. (1967) or Stierlin (1979), parentification implies an emotional responsibility which is the core of the process. This differentiates it from other processes in terms of impact on the child's emotional development (attachment, security, trust in adults and self-esteem). Instrumental responsibilities without emotional burden don't lead to parentification. These differences will be explored and some psychopathological consequences for the parentified child will be presented in this article.

The concept of "constructive parentification" (Jurkovic, 1997; Le Goff, 1999) is also likely to generate some confusion. According to Le Goff, parentification is constructive when the following elements are present: recognition by parents of the child's contributions, non-overwhelming responsibilities, the temporariness of the situation, and a harmonious relationship between child and parent(s). In the presence of these elements, the child experiences beneficial responsibilities for development and maturity, says Le Goff. Yet, this does not match the previously quoted texts (Boszormenyi-Nagy \& Krasner, 1986; Boszormenyi-Nagy \& Spark, 1973; Bowlby, 1977; Minuchin, 1967; Stierlin, 1979), or the clinical practice reality. Certainly, the degree of parentification may vary and all parentified children are not affected in the same way. But applying this label to dynamic family contexts in which the child is rewarded for his gifts, has harmonious relationships with his parent(s) and is not burdened with emotional responsibilities, gives a distorted definition of parentification and should perhaps be categorized another way. For example, depending on the type of responsibility endorsed by the child, a "parentalization," an "adultization" or a "delegation" could be used.

By clarifying the parentification process and comparing it to other processes, the purpose of this article is to help therapists and social workers, especially those who work with children and their families on a front-line. Child protective services, schools, and counseling services have to made quick decisions in short periods of time. Therefore, it is crucial to correctly assess the needs of the child and the family before selecting an approach to treatment.

\section{The concept of parentification}

Boszormenyi-Nagy, in Invisible Loyalties, gives a primary definition of parentification: "By definition, parentification implies the subjective distortion of a relationship as if one's partner or even children were his parent. Such distortion can be done in a wishful fantasy or, more dramatically, through dependent behaviour." This definition is based on the central element of relationship "distortion." The author introduces at the outset two fundamental nuances, form and degree. Indeed, to put a partner in a parental position is not the same as placing a child in such a position. There are different 
degrees of parentification, ranging from a simple fantasy of being wrapped and treated as a child to the demanding addictive behavior that others are forced to support. According to Boszormenyi-Nagy, each adult has at times regressive needs but if the adult parentifies a child, the distortion progresses one step further because the generational difference is denied.

Bowlby (1977) underlines this configuration as a source of anxious attachment for the child:

An additional set of conditions to which some such individuals have been, and may still be, exposed is that a parent, usually mother, exerting pressure on them to act as an attachment figure to her, thus inverting the normal relationship. Means of exerting such pressure vary from the unconscious encouragement of a premature sense of responsability for others to the deliberate use of threats or induction of guilt. (p. 207)

Bowlby didn't precisely name it as "parentification," whereas his successor Byng-Hall $(2002,2008)$ identifies a "parentification script" in which the child is expected to fulfill a parental role and take care of the adults (West \& Keller, 1991). For Byng-Hall and for Boszormenyi-Nagy, parentification emerges in an insecure family context, rooted in the insecure attachments of previous generations.

\section{Parentification roles}

(1) The caregiver. Boszormenyi-Nagy distinguished roles of obvious care and those exercised in a more hidden way. The author took the example of a child who had to call the police because his mother was lying on the ground following the blows issued by his father. However, a child may also act in a way that will be less noticed and yet equally intense as a binding agent of the parental couple to avoid separation.

Bowlby (1977) wrote about the caregiver's experience:

Thus, from early childhood, the person who develops in this way has found that the only affectional bond available is one in which he must always be the caregiver and that the only care he can ever receive is the care he gives himself. (p. 207)

(2) The sacrifice or scapegoat role. Boszormenyi-Nagy described the scapegoat role in several texts without synthesising it, and this makes it somewhat difficult to apprehend. The scapegoat individually handles a collective responsibility. He is unfairly forced to assume the responsibility for someone else's mistakes. Most of the time, parents of the "scapegoat child" have experienced trust, reliability, and security issues as a child (they were abused, mistreated, abandoned, or 
neglected). Once they become parents, they want to be better parents than their parents and give their children all they lacked. They also unconsciously expect their child to repair what others have damaged and to restore their faith in human nature. Having such high expectations unintentionally puts the child in a position of assured failure. Faced with this "impossible mission," the only thing that the child can do is disappoint. As the parents do not perceive the weight of their expectations, the child is seen as aggressive, rejecting, ungrateful, and unwilling to give them love. This behavior forces parents to confront their difficult past and early experiences and the child is, therefore, side-lined and blamed even if he tries hard to satisfy them.

(3) The neutral/perfect role. Boszormenyi-Nagy described the silent role that a parentified child can endorse. It is the "good child" or the "perfect child" who never worries the parents and brings them satisfaction. Parents describe this child as "a model of health and performance." However, according to Boszormenyi-Nagy, one realises that this child's health is a "myth:" "Behind his well-preserved facade he may be struggling with feelings of emptiness, emotional depletion, or depression." Indeed, as the child realizes at an early age that his parent(s) is (are) highly vulnerable, his contribution is to keep all his feelings and thoughts hidden (anger, fear, doubts, anxiety). By claiming nothing and keeping his requests to himself, the child tries to protect the parent, at the cost of an intense loneliness.

(4) The infantilization. This factor is an unexpected form of parentification that makes it barely identifiable. How can someone so young, so immature and without responsibility be parentified? If one understands that the responsibility in question is emotional, the perspective is different; as described by Boszormenyi-Nagy, the dependence of the child actually hides the dependence of the parent(s). The constant need of the child for his parents gives them a sense of value, helps them feel useful and fills gaps left by their childhood (sense of selfworth, recognition, self-esteem).

\section{A process}

At the end of the author's doctoral research (Haxhe, 2010), parentification proves to be a process that develops in the presence of several factors. The 
identified factors are as follows: the sensitivity of the child; the request of (a) parent(s); the factual (events), temporal (life cycle), transactional, and transgenerational context of the family.

\section{Sensitivity of the child}

Generally, the parentified child is called "more sensitive" than other children in relation to parents' and family needs. Therefore, the process does not emerge randomly and there is a "match" between a parent's need and the sensitivity of the child. This sensitivity has been barely explored. Jurkovic (1997) questioned the existence in the development of the child's early features that increase his vulnerability to parentification. He identified the following three variables: temperament (shyness, capacity of adaptation), attachment behavior of the child (the care giver is the child more than the parent), and his ability to take care of someone.

\section{Sensitivity amongst siblings}

Even if parentification is mostly described for one child, the current research has shown that within a family several children can be parentified at the same time in different manners. Indeed, siblings take different roles and support their parents in their own way. In the author's book (Haxhe, 2013), it is shown how siblings share responsibilities in an adaptive organization and how it affects the sibling relationship. Sharing roles, such as "the perfect child" and "the scapegoat," in a same sibling subsystem creates a framework in which, even if each child gives its contribution to the family, mistrust slowly grows within the relationship. If it is difficult for the scapegoat child to identify and recognize the huge responsibility of the perfect child, the opposite is equally true. Therefore, what each sibling experiences is that he is the only one trapped by parental expectations and needs, whereas the other is free. If the roles are more similar (like two caregivers), solidarity and mutual sharing are increasingly possible. The current research and clinical practice experiences have convinced the author that the sibling relationship is a large resource and is often underestimated. If parents are unavailable, too old, or deceased, working with siblings is a highly interesting alternative to individual and family therapy.

\section{Parental request}

According to Michard (2005), parentification is an "essential risk" of the parent-child relationship. If the parent has unfulfilled needs in his childhood and outstanding issues with higher-generations, the temptation will be great to use the gifts of the child to complete the gaps. The unsatisfied needs of the 
parent are mostly emotional needs, such as support and security. The research also reveals an intense need for recognition among some parents. This recognition may be the recognition by relatives (i.e., need for attention, love, the loving gaze of the parent and the need to have its own place in his heart). However, it may also be a need of social recognition that has been missing and could be achieved through the child. Therefore, each of these needs will lead to a particular form of parentification. Nevertheless, the call for the child to fill the role of "good parent" is characteristic in all forms and distinguishes parentification from other processes. Therefore, the weight of the emotional responsibility entrusted to the child, which exceeds its expertise, is inherent in parentification. To fulfill this responsibility, the child must silence its own needs to move toward those of its parent.

\section{The context}

The early death of a grandparent is a primary factor. Already described by many authors, the death of a parent leaves a person with unfulfilled needs, which become a search for satisfaction with their own children. The death of a spouse also seems to activate the process. Sometimes, a person who is strongly attached to someone finds in him/her an important emotional support and may be totally lost after his or her departure. According to Byng-Hall (2002), by being part of a couple, partners can represent an essential resource and support each other to provide "good enough" parenting. Therefore, when the partner is no longer present, the protection that prevented parentification is removed. Disease is another factor, if emotional vulnerability is present or perhaps dormant since childhood, disease can be an activator and strengthens the needs and expectations of the parent.

Therefore, based on the components of the parent-child relationship (sensitivity of the child, the parent's expectations), the author proposes loss in its various forms is an activating factor. Besides loss caused by death, some losses are more "ambiguous" (divorce, degenerative disease, immigration) as described by Boss (1999) or D’Amore (2010).

\section{Parentification and related processes}

To properly discriminate the various processes, one needs to ask themselves specific questions, including: What type of responsibilities are held by the child? In what context? What are the parental expectations? Asking these questions will help us to identify the singularity of each process and complete the evaluation grid proposed next: 


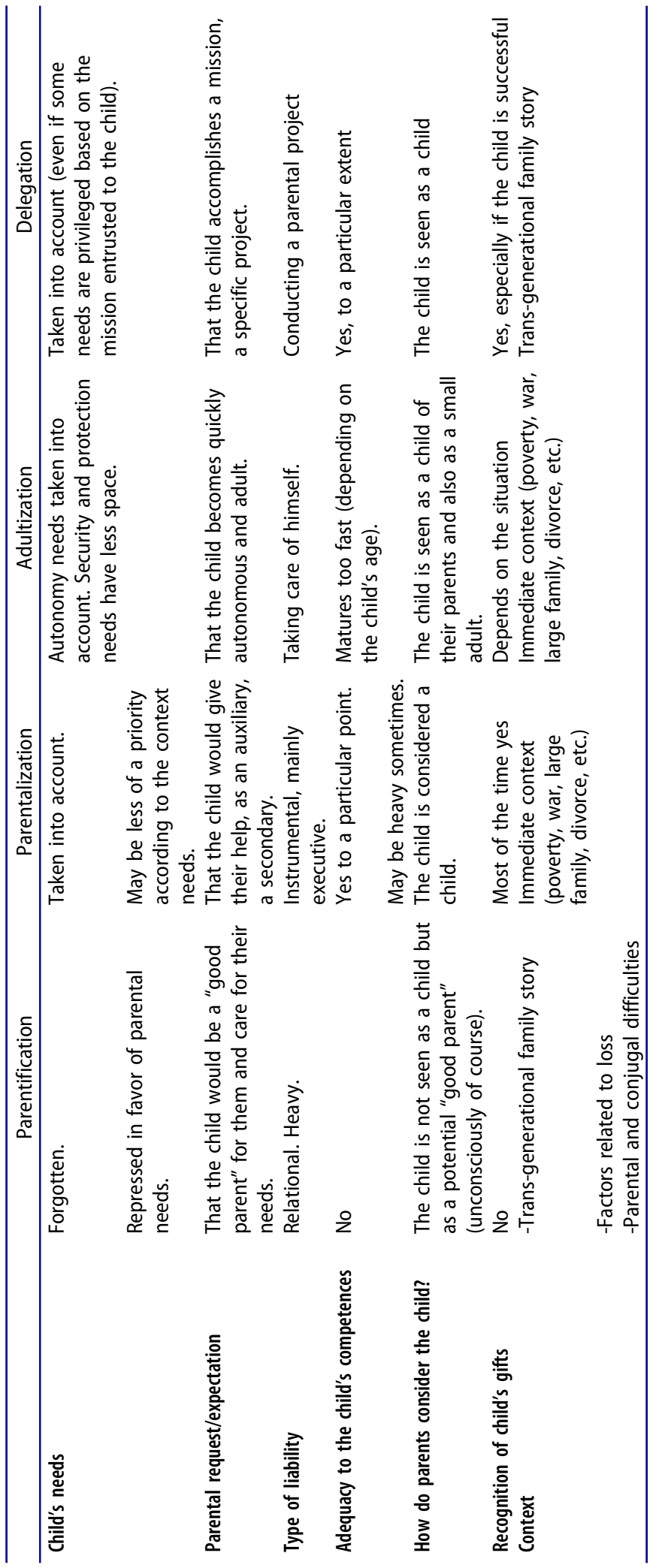




\section{Parentification}

Consideration for the child's needs is a crucial criterion to identify parentification. In other processes these needs are taken into consideration more or less often, parentification; however, requires putting the child's needs to one side in order to focus on the parent's needs.

The expectation of the parent is for the child to be a good parent to him. Being a good parent to a parent is to satisfy their unfulfilled needs in terms of attention, support, recognition and affection. The priority given to the parent is viewed by the child as a matter of life or death when he perceives his parent to be in emotional and/or physical danger, or when the well-being of the parent depends on his response. This perception is the core of the relational responsibility that the child endorses, the importance of which far exceeds what he is able to give, but that he cannot afford to ignore.

Therefore, relational responsibility is another inherent element of parentification, because of its heaviness and its incompatibility with the skills and needs of a child. Moreover, recognition by the parents for what the child does is seldom received. This lack of recognition from the parent is due to their difficulty to acknowledge the unspoken demand they put on the children. This aspect is a therapeutic goal in itself.

What is the impact on a child's development? The relational responsibility can be really heavy to bear. If the child considers that happiness or the life of his parent(s) depends on him, the generated anxiety is likely to be huge. For example, a parent with suicidal thoughts and/or suffering from depression, addiction, anorexia or any other symptom putting him in mortal danger, will conduct the child to focus on his parent's needs and not to miss a sign.

Moreover, the child will, one day, face his inner emptiness. Because parentified children have no space to feel their own emotions, the True Self of the child can't express itself, inducing loneliness. As an adult, this child doesn't know what he likes, as he is not accustomed to take care of his own needs (Miller, 1983). Depressive feelings, low self-esteem and guilt are generated by the gap between the Ego Ideal and the reality of their acts. Then, the suicidal risk must not be ignored.

\section{Parentalization}

Parentalization is an extension of the "parental child" described by Minuchin in Families of the Slums (1967). The concept refers to the role of a child in some large and vulnerable families that are defined as "disorganized." In these chaotic families living in instability, parents often have a limited parental role due to particular conditions. Children then sometimes rely on their parents and sometimes not, because they are sometimes present and 
available and sometimes overwhelmed. In this context, the "parental child" is the one to whom authority is attributed by parents or siblings. The role concerns an instrumental and/or executive function, mainly with regard to brothers and sisters. Minuchin never mentions a role exercised in the emotional sphere, particularly in the care of a parent.

The author describes the parental child as a child who has been temporarily delegated a function and a hierarchical position usually assigned to the parental subsystem. The child joins the parental subsystem for a period of time with a defined role, and the parental function temporarily entrusted to him is instrumental because it concerns giving help to his brothers and sisters. The two points on which Minuchin emphasizes are the following: clarity of boundaries and the explicit expression of "who has responsibility and authority." In the presence of these two elements, Minuchin considers that the system may operate quite well with a parental child, as well as with the presence of a very helpful grandmother.

The support brought by the child to the parental subsystem is in this case contextualised through economic and cultural data. Family status cannot be considered separate from its cultural, situational (related to a transitional crisis for example) or temporal context. Minuchin (1998) comments:

The attribution of parental authority to a child is a natural arrangement in large families, families with a single parent or in families where both parents work. The system can work well. Young children are well cared for and the parental child may develop responsibility, competence and autonomy beyond his years. (p. 115)

Therefore, if the role played by the parental child is temporary, defined, and contextualized, it can be an opportunity to develop an early sense of responsibility and autonomy.

Minuchin considers that the situation of a family with a parental child can become problematic if the delegation made to the child is not explicit and if parents "abdicate, leaving the child to become the main source of advice, authority and decisions." In this case, requests that are made of the child may exceed his competences but also be in conflict with his own requirements and needs.

The addition we make in this paper of the suffix "-tion" to the word "parental" refers to a movement and suggests that there is a process. The "parental-iza-tion" refers to the movement toward the "parental," to what makes the parental function. This can be a dynamic process, provided that the child's age and the weight of what is asked is not too heavy.

Parentalization calls the child, not to be a parent as in parentification, but rather to assist the parents in their parental function and to be a parental aid. Parents are then present as parents and consider the child as a child but ask him to join them to be stronger at particular times for particular things. The performance of this function can be a source of maturation by learning some competences. 


\section{Adultization}

The word "adultization" encompasses many meanings in the current language. It is sometimes used to evoke parentification, but it can also refer to the transition from adolescence to adulthood or the enticing of parents to turn their child into a "mini-adult." In the present article, "adultization" refers to the movement toward what is adulthood. This movement will vary according to the age of the child. For a teenager, the process is dynamic and adaptive. For a young child, the process evokes a fast maturation that does not consider some of the child's needs such as protection and dependency. The "adult child" is asked to become quickly autonomous by teaching himself within a community that is not always available to supervise.

Being an adult is not being a parent and vice versa, and that is why adultization should not be confused with parentification. The parental request is not the same in both cases. If the parentified child is expected to be a parent for his parent(s), the adult child is expected to grow up faster and be autonomous, within some specific contexts (precarious financial and/or social situations, single-parenting, parent[s] working hard).

\section{Delegation}

"Delegation" is a concept introduced by Stierlin (1979). In its dynamic form, delegation is a mission entrusted by parents, which somehow gives meaning and direction to their child's lives ("I would like you to do university studies, I would be so proud," says a workman father to his daughter). Therefore, delegation is the action to assign a load or mission. Like in other processes, everything depends on the type of entrusted mission and the adequacy of the skills of the child. If the mission is too demanding and/or not adjusted to the child's ability, it can mutate into parentification. Again, the degree of consideration for the needs of the child is a useful marker to distinguish between parentification and delegation, as well as the type of parental expectation. Sometimes, the parental project takes priority over individual needs, and the only thing that matters is to accomplish the project, whatever the child wants or experiences. The movie "Black Swan" by Handel and Aronofsky (2010) is an example of a delegation process crossing the lines and evolving into parentification. In the movie, the mother is a former dancer who didn't achieved the level that she wanted. Narcissistically hurt, she needs to achieve her project and she will do it through her daughter. Nina, a very promising dancer, becomes the target of the mother's projections and hopes and is forced to accomplish her mother's project. Aronofsky shows how mother and daughter are almost the same character and how the mother has a difficult time letting her daughter live her own life. Being an opera star is so vital that nothing else matters. Nina does not get the chance to live a normal teenage 
life, as her mother forbids any contact with people who could distract her from her project. The film illustrates the mutation from delegation to parentification, as Nina's life is oriented toward her mother's narcissistic need.

\section{Case study ${ }^{1}$}

\section{Presentation}

Lisa is 10-years-old. She lives with her mother, Ms. M., and her younger halfbrother aged 18 months, Jason. Her parents have been separated for 8 years, and she barely sees her father. Social services send Lisa and her family to a child protective service because she misses school very often. If she does not go to school more regularly, she could be placed in a foster family or a home for children. Lisa's mother explains that she does not understand why her daughter does not go to school. She forces her to go but nothing works. Lisa has some trouble with children in her class, she does not seem to be wellliked, and these issues could be the reasons why she does not want to go, according to her mother.

After a few appointments, we learn that Ms. M. has been depressed for 4 years because of the loss of a son. Lisa was 6 at the time. Since then, Ms. M. describes a huge difficulty to rebuild her life and to go on. Life has been lighter for a while after the birth of Jason, but now she feels depressed again, sometimes with suicidal thoughts. She would like a new partner but she doesn't trust people easily. Her family are seen as a threat more than as a support, as they have called the social services with their worries for Lisa. Ms. M. feels betrayed and explains how she always felt rejected by her mother, presumed to favor her sister. Her father, more affectionate, died when she was 14-years-old.

If her mother does not feel good, Lisa stands by her, trying to entertain her, proposing activities to make her get out of bed. Most of the time, she proposes to go to the park or to do some shopping. Even if she doesn't understand why Lisa does that, Ms. M. confesses that Lisa is a confident and a source of reassurance.

\section{Diagnosis}

Let's take a look at this example through the evaluation grid.

- Child's needs: For Lisa, standing by her mother and trying to animate her to avoid suicide is the absolute priority; her life as a child with friends is a minor concern.

\footnotetext{
${ }^{1}$ This is a composite of a number of cases, and does not represent any real individuals or families
} 
- Parental request: Although Lisa's mother does not overtly ask for her presence and care, she confesses that Lisa is a confident and a source of reassurance. Her relational background is marked by loss, lack of trust, and feelings of rejection.

- Type of liability: Lisa puts her needs aside and tries to be a good parent for her mother.

- Adequacy to the child's competences: Too heavy as it impedes the child's development.

- How do parents consider the child? Lisa is seen as a potential "good parent" (unconsciously of course), providing the attention and care, which has always been missing or has been lost.

- Recognition of child's gifts: If the mother acknowledges that Lisa is a source of reassurance, her relational responsibility is not seen as such by the mother, who states that she does not understand why Lisa does not go to school.

- Context: Several losses. Lisa's mother has lost her father, a child and is single.

All criteria converge in a diagnosis of parentification. The emotional responsibility, the lack of positive social relationships with children of her age, and the absence of recognition have consequences on Lisa's development; she's anxious, overweight, and tends to blame herself for everything that goes wrong.

It is a bit more difficult to decide on Jason's parentification, as he is only 18 months. If the author had used an observation instrument like the Lausanne Trilogue Play created by Fivaz-Depeursinge and Corboz-Warnery (2001), evaluating interactions between toddlers and parents, there would certainly be more indications. As a therapist, the author's feeling is that being the cute, smiling, funny, and reassuring child could also parentify Jason.

\section{Family sessions}

The author worked with the family for 1 and $1 / 2$ years, with various steps. The first step was the recognition of the mother's suffering and the investigation of her childhood experience and unfulfilled needs. At the beginning, Ms. M. didn't seem to measure the burden on Lisa's shoulders. But after the author explored and recognized her own feelings of loneliness as a child and her lack of trust in people, she progressively opened herself to the inner world of her daughter. The temptation is great to push the parent, as soon as possible, to recognize the child's contributions toward him. However, doing so without first connecting to his own experience is not only inefficient but also moralizing and, therefore, violent for the child who protects his parent.

The second step opened a dialogue between the mother and her children, through the recognition of the impact of her depression on their relationships, the recognition of Lisa's worries and attempts to help her, and the recognition 
of Jason's attempts to make her smile by his clown attitudes (obvious during the therapy sessions).

The author has also considered the role of Lisa's father, barely present in her life. The father has remarried and has had another child. According to the mother, he has no time for Lisa. The author invited him but he didn't show up. However, the author had phone contacts with him and he got more and more involved in the family work with time. At the end of the sessions, Lisa was going to her father's place every other weekend. Without the family work with the mother, this would have remained impossible, as the mother needed Lisa always around her and as Lisa was afraid to leave her alone.

Progressively, as trust was growing between mother and children, they began to exchange more and more feelings and questions during the sessions. One day, as Ms. M. was saying that she was feeling better, Lisa stood up, went toward the blackboard and started a Hangman game. She put the first letter "W" and asked her mother to play. The mother finally found out the word "WORRY" and asked Lisa what she was worried about. Lisa responded "I don't know how to see if you feel good or not, so I don't know when I have to worry or not." This was a turning point of the therapy because an authentic dialogue was created. We then asked Lisa if her mother could say or do something specific, a little thing as much concrete as possible, to let her know how she was feeling and how she needed help. The objective was to relieve Lisa from worrying all the time, in order to give some space to her own needs, life and interests, while respecting her desire to care for her mother. Indeed, the goal of this kind of therapy is not to make a "care-ectomy" but to help the child to help his parent, and to be recognized for his it.

Lisa asked her mother to tell her when she felt down. Ms. M. committed to use the code word "down" and to call someone for help when Lisa was not there.

Another part of the work with the family was to connect Ms. M. to a network of psychological, relational and material help to support Lisa in her efforts to help her mother. Helping the parent is helping the child, as the latter could not benefit from support received by them alone if he/she is still anxious for the parent. If the parent increases his trust in other people, the relational responsibility of the child becomes lighter and more suitable. This also strengthens the trust between the parent and the child and allows both of them to invest in and outside their relationship. Progressively, Lisa's mother felt better, searched for a job and had more activities. Lisa, for her part, went back to school and was less anxious for her mother.

\section{Conclusion}

This article underlines the need for a better distinction between parentification and some related processes. Parentification is different not only in its form but also in its call for therapeutic care, as each family member struggles with 
suffering and loneliness. The relational responsibility endorsed by the child, tends to generate anxiety and depressive feelings when the child realizes that he/she is not equal to the challenge. The parent for his part fights with various relational problems, loneliness, lack of self-confidence, trust in others, loss and more, which can lead to diverse psychological and/or physical symptoms. The case example illustrates how family therapy, here conducted with the model of the contextual therapy of Boszormenyi-Nagy proves to be useful. The core of the therapy is the engagement of the child and parent(s) in an authentic dialogue about each other's experience and feelings, but also their commitment to act in a way that will secure the relationship. If words are important, acts (even minimal) have way more power to build a more trustworthy, reliable, and reciprocal relationship. In the case example, the commitment of the mother to admit and say when she was really down and to call someone, allowed Lisa not to worry all the time as she used to. She could go back to school without wondering constantly about what her mother was doing. On her side, Lisa could stay present for her mother and still caring for her but in a less burdening way. This type of work strengthens the family bonds here and now, but also for future generations (having in mind Lisa and Jason becoming parent at their turn).

\section{Limits and perspectives}

The propositions presented in this article are based on the clinical practice and on case studies from the current doctoral research. Extending the observations to a larger population would be interesting. For example, the author would like to create a parentification scale with a discriminative power regarding the several processes presented here. Also, items covering less known forms of parentification such as the scapegoat or the perfect child would be of a great interest. To date, these roles of parentification are not detectable with a scale. The caregiver and go-between roles being the most "popular," the scales seem to be constructed mostly around them.

Chase (2004) also underlined that the current instruments tend to evaluate parentified role behaviors independently of the sociocultural and ethical context in which they occur. The author would then like to create a scale exploring the elements of the context, such as the relational background on three generations (reciprocal trust and care, quality of attachment, emotional responsibilities, recognition, fairness, and justice).

\section{References}

Borszomenyi-Nagy, I., \& Krasner, B. (1986). Between give and take. NY, NY: Brunner/Mazel. Boss, P. (1999). Ambiguous loss: Learning to live with unresolved grief. Cambridge, MA: Harvard University Press. 
Boszormenyi-Nagy, I., \& Spark, G. M. (1973). Invisible loyalties. NY, NY: Harper \& Row. Bowlby, J. (1977). The making and breaking of affectional bonds: I. Aetiology and Psychopathology in the light of attachement theory. British Journal Psychiatry, 130, 201210. doi:10.1192/bjp.130.3.201

Byng-Hall, J. (2002). Relieving parentified children's burdens in families with insecure attachment patterns. Family Process, 41(3), 375-388. doi:10.1111/famp.2002.41.issue-3

Byng-Hall, J. (2008). The significance of children fulfilling parental roles: Implications for family therapy. Journal of Family Therapy, 30, 147-162. doi:10.1111/j.1467-6427.2008.00423.x

Chase, N. (2004). Burdened children. Theory, research, and treatement of parentification. Thousand Oaks, CA: Sage publications.

D’Amore, S. (2010). Les nouvelles familles comme systèmes relationnels endeuillés: Pour une clinique de la perte. Thérapie Familiale, 31(1), 13-25. doi:10.3917/tf.101.0013

Fivaz-Depeursinge, E., \& Corboz-Warnery, A. (2001). Le triangle primaire: le père, la mère et le bébé. Paris, France: Odile jacob.

Handel, A. \& al. (Producers), \& Aronofsky, D. (Director). (2010). Black Swan (Motion Picture). Fox Searchlight Pictures.

Haxhe, S. (2010). Etude du processus constitutif de la parentification (Doctoral Thesis). University of Liège, Liège, Belgium.

Haxhe, S. (2013). L'enfant parentifié et sa famille. Toulouse, France: Erès Relations.

Hooper, L. M., Doehler, K., Wallace, S. A., \& Hannah, N. J. (2011). The Parentification inventory: Development, validation, and cross-validation. American Journal of Family Therapy, 39(3), 226-241.

Jurkovic, G. (1997). Lost childhoods. The plight of the parentified child. New York, NY: Routledge.

Le Goff, J. F. (1999). L'enfant, parent de ses parents. Parentification et thérapie familiale. Paris, France: L'Harmattan.

Michard, P. (2005). La thérapie contextuelle de Boszormenyi-Nagy: Une nouvelle figure de l'enfant dans le champ de la thérapie familiale. Bruxelles, Belgium: De Boeck.

Mika, P., Bergner, R., \& Baum, M. (1987). The development of a scale for the assessment of parentification. Family Therapy, 14(3), 229-235.

Miller, A. (1983). Le drame de l'enfant doué. Paris, France: Presses Universitaires de France. Minuchin, S. (1998). Familles en thérapie. Toulouse: Erés Relations.

Minuchin, S., Montalvo, B., Guerney, B., Rosman, B., \& Schumer, F. (1967). Families of the slums. An exploration of their structure and treatment. New York, NY: Basic Books.

Sessions, M. W., \& Jurkovic, G. J. (1986). The parentification questionnaire. Available from Gregory J. Jurkovic, Department of Psychology, Georgia State University, University Plaza, Atlanta, GA, USA.

Stierlin, H. (1979). Le premier entretien familial. Théorie, pratique, exemples. Paris, France: Editions universitaires J.P. Delarge.

West, M. L., \& Keller, A. E. (1991). Parentification of the child: A case study of Bowlby's compulsive care-giving attachment pattern. American Journal of Psychotherapy, 145(3), 425-431. 